to be extended during next summer, and we shall probably soon have the satisfaction of knowing whether our climate is suitable to its tastes. If so, it will probably obey the mandate of increasing and multiplying ; but its tendency will be towards deplenishing rather than replenishing the earth. The prospect is not exactly nice, but we may take some comfort from Prof. Riley's expressed opinion that the Hessian fly will not prove a very serious plague to British agriculturists.

Downton, December Io.

JOHN WRIGHTSON.

\section{THE REPRODUCTIVE ORGANS OF ALCYONIDIUM GELATINOSUM.}

IN some specimens of the Polyzoon Alcyonidium gelatinosum dredged last summer, I noticed that the colony, in place of being nearly homogeneous in colour and semi-translucent, as is usually the case, had a blotched appearance, caused by the presence of a number of small rounded spots of an opaque grayish-white or pale yellow colour. These average about $0.5 \mathrm{~mm}$. in diameter, and are scattered irregularly through the colony. On teasing up a small part in sea-water, and on making a few rough sections of the living colony, I found that the opaque spots were cavities filled with fully developed active spermatozoa. No ova were visible in the polypides of any of the parts examined, so these colonies were cvidently in the condition of sexually mature males. It at once occurred to me that this species of Alcyonidium might be unisexual-some colonies male and others female-the males being distinguishable when mature by their spotted appearance. The specimens were preserved for future examination.

On returning to Liverpool, and looking up the literature of the subject, I find that Hincks states ("British Marine Polyzoa," introduction, p. lxxxvi.)that "Alcyonidium gelatinosum, according to Kölliker, is unisexual," and I gather from the context that it is the individual polypides that are unisexual, and not the whole colony. Hincks, however, does not give a reference to any paper by Kölliker, and I have not been able to find in the literature of the Polyzoa, or in the bibliographies I have consulted, any paper of Kölliker's which would be likely to contain observations on the reproduction of Alcyonidium ; therefore I am still uncertain how far Kölliker's remark is intended to apply - to the whole colony, or only to the individual polypides. I know of no other investigations on the subject.

I have now examined a number of thin sections, of both the spotted colonies (including the one formerly dissected) and the usual translucent ones, and I find :--

(I) In the spotted colonies there are a number of greatly distended polypides, with their coeloms filled with fully developed spermatozoa. There are also a few ordinary large, but not distended, polypides, containing each a few young ova.

(2) In the ordinary clear colonies there are neither ova nor spermatozoa to be found.

It is evident, then, that the colony is hermaphrodite, whatever the polypide may be. But it is also evident that the spotted colonies are virtually males. Their spermatozoa are fully developed, while their ova are still quite immature. Probably, then, Alcyonidium gelatinosum is, like many of the Compound Ascidians, an hermaphrodite in which the reproductive systems arrive at maturity at different times in the life-history. Most of the Compound Ascidians in which I have found this the case are proterogynous (the female organs maturing first), but Alcyonidium gelatinosum appears to be proterandrous. If the polypides are unisexual, then the proterandry refers only to the colony as a whole, but it is possible that each polypide may be a proterandrous hermaphrodite, developing ova after it has got rid of the spermatozoa. I hope to investigate this matter further by keeping some colonies alive at the Puffin Island Biological Station, and examining their condition from time to time.

In Alcyonidium gelatinosum both the ova and the spermatozoa occur in ordinary polypides, and not, as Hincks states is the case in the closely related species $A$. mytili, in " gonœcia" (cells contain. ing no polypides). In my sections the alimentary canal and tentacles are found cut across here and there in the masses of spermatozoa. The large cavities containing the spermatozoa are evidently ordinary polypides, with the cœlom greatly distended.

W. A. HERDMAN.

\section{SOCIETIES AND ACADEMIES. LONDON.}

Royal Society, December 15.- "Note on the Development of Feeble Currents by purely Physical Action, and on the Oxidation under Voltaic Infuences of Metals not ordinarily regarded as spontaneously oxidizable." By Dr. C. R. Alder Wright, F.R.S., and C. Thompson, F.C.S.

The authors have noticed that if two or more different kinds of aerration plates be set up on the surface of the fluid contained in a shallow basin in which the oxidizable metal is immersed, and sufficient time be allowed to elapse to enable the films of air attracted to the aerration plates to attain a condition of equilibrium, different constant values are usually obtained for the E.M.F.'s generated by opposing to the oxidizable metal first one and then the other of any given pair of aëration plates, the currents generated being rendered throughout of too small density for "running down" to take place during the observations by interposing a large resistance in the circuit. If when this state of constancy has been attained the two aëration plates be opposed to each other with a considerable resistance in circuit, a current passes from the one giving the higher value when opposed to the oxidizable plate through the external circuit to the other; this current at first is of such magnitude as to correspond exactly with the E.M.F. due to the difference between the E.M.F.'s exhibited when the two plates respectively are opposed to the oxidizable metal; but after some time it gradually diminishes; even after several days, or even weeks, however, it is usually still measurable ; and if a miniature silver voltameter be included in the circuit, in many cases an appreciable amount of crystalline silver is found to be slowly deposited on the negative electrode of the voltameter, which may conveniently be a thin gold wire immersed to a depth of a few millimetres in silver-nitrate solution, a silver plate or wire forming the positive eiectrode. Various experiments are described in illustration.

It is obvious that during the passage of a current the dilute sulphuric acid between the two plates must be electrolysed, so that hydrogen would tend to be liberated on the surface of the plate acquiring the higher potential, and oxygen on that of the other; the hydrogen whilst nascent would necessarily be more or less completely oxidized to water by the oxygen of the film of condensed air; so that on the whole the net chemical action in the cell itself would be either nil (if all hydrogen were so reoxidized) or one absorbing heat (if some of the hydrogen escaped oxidation). The oxygen slowly evolved would escape as such, being dissolved by the surrounding fluid. The effect of this should accordingly be that the efficiency of the air-film on the first plate would be more or less depreciated, and that on the second exalted ; in point of fact, if the two aeration plates in such an arrangement which has been generating a current for some time be (by means of an appropriate switch) disconnected from one another and successively opposed to a given oxidizable plate, the one does give a considerably lower and the other usually an appreciably higher value than the constant ones previously ob. tained (before the two aëration plates were directly opposed to one another) on opposing each severally to the oxidizable metal; whilst on allowing the cell to stand for some time generating no current, the lower value gradually rises and the raised one falls until sensibly the old constant values are again obtained.

When silver plates are used in conjunction with a fluid capable of dissolving silver oxide (such as dilute sulphuric or acetic acid or ammonia solution), distinctly larger amounts of current are usually developed than with platinum or gold plates, and simultaneously silver passes into solution, the plate acquiring the lower potential diminishing in weight, and, in short, behaving precisely as though it were an oxidizable metal, such as zinc or copper. Obviously this is due to the circumstance that with silver the ion liberated attacks the metal of the plate acquiring the lower potential ; but the remarkable part of the action is that this attack is only partial, so that the amount of silver dissolved is invariably less than that equivalent to the current passing, i.e. less than that deposited in a silver voltameter included in the circuit.

Various illustrative experiments are described which show that the difference between the silver dissolved and that deposited by the current is relatively much larger with the weakest currents.

It is obvious that if silver will dissolve in acids, \&c., under the comparatively feeble oxidizing influence of an aëration plate, 
much more rapid solution might be anticipated by substituting for such a plate platinum immersed in a powerfully oxidizing fluid such as strong nitric acid, or sulphuric acid solution of chromic anhydride. In point of fact, the authors have found that on setting up such cells where the silver was immersed in dilute sulphuric acid (i.e. Grove's cell with silver instead of zinc, and so on), electromotors of notable power are produced, at any rate until the silver plate becomes coated with sparingly soluble sulphate. Even in these cases, however, perfect correspondence between the amount of silver dissolved and that deposited in a voltameter included in the circuit does not subsist, the latter being always measurably the greater.

Just as silver is capable of being dissolved in an appropriate fluid when opposed to an aerration plate, so may several other metals not ordinarily prone to atmospheric oxidation; thus mercury with dilute sulphuric acid a; fluid, and an aëration plate of platinum sponge, generates a measurable continuous current, forming mercurous su'phate in so doing, so that after some time the liquid becomes turbid through separation of that sparingly soluble salt, and the filtered fluid precipitates calomel on addition of dilute hydrochloric acid. Acetic acid acts similarly, but far less energetically. Potassium cyanide solution, on the other hand, causes a much more rapid solution of mercury, forming mercuric potassiocyanide; it is noticeable that in this case only roo parts of mercury go into solution for 108 of silver deposited in the voltameter, whereas when sulphuric acid is used 200 parts of mercury become sulphate per 108 of silver deposited.

If gold be substituted for mercury in this latter arrangement, rapid solution takes place with formation of aurocyanide of potassium, 196 parts of gold being dissolved per 108 of silver thrown down in the voltameter. Palladium behaves precisely as gold, 52 parts of metal being dissolved per ros of silver deposited; local action sometimes causes in each case a slight excess of amount dissolved relatively to the current passing, the opposite result to that observed with the silver cells above described.

Of course, if more powerful oxidizing agents are used than simple aëration plates (such as platinum in sulphuric-chromic solution) the action goes on in all such cases still more rapidly.

"On the Functions of the Occipital and Temporal Lobes of the Monkey's Brain." By Dr. Sanger Brown and Prof. F. A. Schäfer, F.R.S.

The authors gave an account of experiments upon the brain of monkeys, involving the removal of the occipital and temporal lobes respectively. These experiments show that removal of the whole of one occipital lobe produces permanent hemiopia and that removal of both occipital lobes produces complete and permanent blindness of both eyes; and, further, that for the production of these effects it is not necessary that the angular gyrus should be involved in the lesion.

They also show that not only the superior temporal gyrus but even the whole temporo-sphenoidal lobe can be removed on both sides of the brain in monkeys without producing any appreciable permanent effect on hearing.

The reading of the paper was illustrated by diagrams exhibiting the extent of the lesions, as well as by casts of the brains.

Royal Meteorological Society, December 2I.-Mr. W. Ellis, President, in the chair.-The following papers were read : -The mean temperature of the air at Greenwich, from September 181 I to June 1856 , by Mr. H. S. Eaton. This is a discussion of the meteorological journals of the late Mr. J. H. Belville, and those of the Royal Observatory. The general results of this investigation are :- (I) That there was no appreciable change in the mean annual temperature of the air at Greenwich in the period I8I 2 to 1855 inclusive. (2) That on the eminence on which the Royal Observatory is situated the average temperature at night, or rather the early morning, is in all cases higher than over the lower grounds. (3) That with a north-wall, or possibly a north-window exposure, higher maximum temperatures are found at the lower stations. (4) That the movements of the thermometer are retarded with a north-wall exposure as compared with an instrument on an open stand, especially where the situation is a confined one, the indications of the thermometer not following changes of temperature so promptly owing to the modifying influence of the adjacent building.-Report on the phenological observations for the year 1887 , by the Rev. T. A. Preston. The past season was a most exceptional one. For flowers it was disastrous; fruit was generally a failure, though there were exceptions ; those kinds which promised well turned out very small or spoilt by insects. Vegetables were universally poor, roots were destroyed by insects or drought, and green crops soon passed off. The wheat crop, however, was better than was expected. Barley on light lands was poor, but that which was sown early was satisfactory. Meadow hay was not up to an average crop, but clover and seed hay were much more nearly so. In Kent the fruit crops turned out lighter than usual, but the prices have ruled higher.--Earth tremors and the wind, by Prof. John Milne, F.R.S. The author has made a delailed examination of the tremor records obtained in Tokio, and compared them with the tri-claily weather maps issued by the Imperial Goverment of Japan. From this comparison the following conclusions have been drawn:-(I) Earth tremors are more frequent with a low barometer than with a high barometer. (2) With a high barometric gradient tremors are almost always observed, but when the gradient is small it is seldom that tremors are visible. (3) The stronger the wind the more likely it is that tremors should be observed. (4) When there has been a strong wind and no tremors the wind has usua!ly been local, of short duration, or else blowing inland from the ocean. (5) When there has been little or no wind in Tokio and yet tremors have been olsserved, in most cases there has been a strong wind in other parts of Central Japan. (6) From 75 to 80 per cent. of the tremors observed in Tokio may be accounted for on the supposition that they have been produced either by local or distant winds. (7) The only connection between earth tremors and earthquakes in Central Japan is that they are both more frequent about the same season. - Pressure and temperature in cyclones and anticyclones, by Prof. H. A. Hazen. The author has made a comparison of the observations at Burlington and on the summit of Mount Washington, U.S.A., and as the result of a study of aboat 4000 observations from two days before till two days after the passage of cyclone and anticyclone centres, he has arrived at the following conclusions:-(r) In both cyclones and anticyclones the pressure lags from so to I I hours at the summit of Mount Washington. (2) The temperature change at the base precedes very slightly the pressure change, but at the summit the change occurs nearly: 24 hours earlier. (3) The temperature appears to be a very little earlier at the summit than at the base, and certainly varies much more rapidly at the former. (4) In a cyclone the difference in temperature between base and summit is less than the mean before the storm, but the difference rapidly increases after the centre has pasied. Just the contrary is true in an anticyclone. (5) The total fall in pressure in a cyclone at the summit very nearly equals that at the base, and likewise the rise in an anticyclone. (6) The fluctuation of temperature-that is, from the highest to the lowest--at the summit is double that at the base in a cyclone; but it is only a little greater in an anticyclone.

\section{EDINBURGH}

Royal Society, December 5.-The Hon. Lord Maclaren, Vice-President, in the chair. - After reading an opening address, the Chairman presented the Victoria Jubilee Prize to Sir W. Thomson, for his contributions to the Society's publications on various subjects in hydrokinetics. - Sir W. Thomson read a paper on Cauchy's and Green's doctrine of extraneous pressure to account for Fresnel's wave-surface. The object of his investigation was to place Green's treatment of the subject on a more satisfactory basis than it had been left by its author.--Sir W. Thomson also exhibited models of the minimal tetrakaidekahedron, a figure which he discusses in the Philosophical Magazine for this month.-The second part of a paper on micro-organisms, by Dr. A. B. Griffiths, was communicated by Prof. Crum-Brown. - Prof. Wallace laid on the table a paper on the blackening of the skin of domesticated animals in tropical regions.

\section{PARIS.}

Academy of Sciences, December 19.-M. Janssen in the chair.-Generation of algebraic surfaces of any order, by $M$. de Jonquières. The theorem here demonstrated supplies a fresh instance of the intimate and essential part played by the p coperties of numbers in several questions of general geometry, and especially in those concerned with the generation of surfaces and curves, as well as with the number of double and multiple points with which the latter may be endowed.-Reply to M. Wolf's communication entitled, "Comparaison des divers systèmes de synchronisation des horloges astronomiques," by 
M. A. Cornu. The regulating apparatus introduced into his system of synchronizing clocks by M. Cornu, and objected to by M. Wolf as useless and even inconvenient, is shown to be free from these drawbacks, and in fact indispensable for strict accuracy. To these remarks $M$. Wolf replies that the system at work at Greenwich for twenty-seven and in Paris for seventeen years dispenses altogether with any such arrangement as that proposed by M. Cornu.-On the cause of the deviation of the arrows indicating the direction of the wind on synoptical charts of cyclones, by M. Faye. This deviation is traced entirely to the friction or resistance of the ground over which the cyclone is moving, and harmonizes in no way with the erroneous hypothesis of ascending cyclones. It is greater on land than at sea, and imperceptible in the case of waterspouts and true tornadoes. It also diminishes with the distance from the centre of the cyclone, disappearing altogether near the central calm.-On the state of the sulphur and phosphorus present in plants, in the ground, and in cultivated soil, and on their quantitative analysis, by MM. Berthelot and André. Having already studied the relations of potassium and nitrogen to the vegetative functions, the authors here deal in the same way with sulphur and phosphorus. The question is treated especially with a view to determining and analyzing the complementary manures best suited for restoring the fertility of exhausted lands. -Note, by M. Albert Gaudry, on the discovery of a gigantic turtle by Dr. Donnezan. This specimen was found, with numerous other fossils, in the Middle Pliocene of Perpignan during the recent excavations connected with the erection of the fortress of Serrat in the Eastern Pyrenees. The carapace, $\mathbf{I} \cdot 20$ metre long, was extracted with great difficulty from the hard rock in which it was completely embedded, the innumerable fragments being carefully pat together by Dr. Donnezan, by means of about a thousand brackets. This turtke, which he has named Testudo perpiniana, and which he has presented to the Paris Museum, considerably exceeds its living congeners, being equal in size to the $T$. grandidier, a sub-fossil species found in Madagascar. Its survival down to the close of the Middle Pliocene is important for the study of the Glacial period, tending to show that the south of France even then still enjoyed a warm climate. -Experiments with a new hydraulic machine employed for irrigating-purpo es, by M. A. de Caligny. By means of this apparatus, which is a modified form of that described by the author in the Comptes rendus for December 18, 1882, wate with a normal fall of 2.40 metres may be raised to a height of 9.45 metres above the level of the upper s ream. - On the degrees of oxidation of chromium and manganese in their fluorescent compounds, by M. Lecoq de Boisbaudran. With a view to solving this question the author describes certain experiment which he has made chiefly with alumina and chromium, gallina and chromium, magnesia and chromium, alumina, potassa, and manganese, lime and manganese ; confining him self for the present to a statement of the facts observed. -Elements and ephemeris of the planet Anahita, 270, by M. E. Viennet. By means of the ephemeris deduced from the already published provisional elements the author has been enabled to compare all the observations made down to November I6, and thus determine six normal places for October 12, 15, 18, 21, 27, and November 16. With these fresh elements an ephemeris has been calculated, by which astronomers will be enabled to observe the planet down to the end of the present opposition. The magnitude should then be about II or I2.-On the value of the solar parallax deduced from the observations taken by the Brazilian Missions during the transit of Venus in I882, by M. Cruls. From the reports of the observations made at the three stations of St. Thomas (West Indies), Olinda (Brazil), and Punta-Arenas (Strait of Magellan), the horizontal equatorial parallax of the sun at its mean distance from the earth is found to be $8^{\prime \prime} \cdot 848-\mathrm{o}^{\prime \prime} \cdot 040=8^{\prime \prime} \cdot 808$. The reports are now nearly printed, and copies may soon be expected in Europe.-On the specific heat of tellurium, by $\mathrm{M}$. Ch. Fabre. These experiments show that under its several forms tellurium possesses much about the same specific heat, at least at a temperature of $100^{\circ} \mathrm{C}$. or thereabouts. But the differences may possibly increase at higher temperatures, and especially near the point of transformation from amorphous to crystallized tellurium. -Study of a specimen of Welsh coal, by MM. Scheurer-Kestner and Meunier-Dolfus. This was a piece of the so-called "Nixom's Navigation," from Glamorgan, which the authors undertook to examine for Mr. Donkin, and which was found to be so pure that it yielded 88 per cent. of hard bright coke, 4.39 of hydrogen, and not more than 69 of sulphur.--On sidereal evolution, by M. Ch. V. Zenger.

\section{BERLIN,}

Physiological Society, December 2,-Prof, du Bois Reymond, President, in the chair.-Dr. Salomon spoke on the physiological action of paraxanthin. Since Fisher's researches have thrown light on the chemical constitution of caffein and theobromin, and shown that the former is trimethyl-xanthis, the latter dimethyl-xanthin, experiments on the physiological action of caffein, theobromin, and xanthin have acquired an increased interest. All these substances produce a double effect when given to a frog-namely, one on the central nervous system, and a curious effect on the muscles, which pass into rigor; the three substances exhibit these properties in graduated deoree, a fact which is sufficiently explained thy the close relationship of their chemical constitution. It hence appeared to the speaker to be a matter of some importance to investigate the physiological action of the two xanthin-derivatives which he had found in urine-namely, paraxanthin and heteroxanthin. From his researches it appears probable that paraxanthin was also a dimethyl-xanthin, that is, an isomer of theobromin; heteroxanthin, on the other hand, had only been obtained in such minute quantities that its chemical constitution could not be determined, but Dr. Salomon suggested that it might be the missing member in the above series of xanthin-derivativesnamely, monomethyl-xanthin. When the somewhat insoluble paraxanthin was administered locally by subcutaneous injection, it produced a stiffness and rigor of the neighbouring muscles: when given in larger doses, some of the animals became sluggish and died, but in many cases they remained uninjured. When given internally, paraxanthin rarely led to any appearance of poisoning, but, when it did, the effect was limited to a stiffening of the fore-limbs and a general sluggishness of the whole animal. Paraxanthin, therefore, exhibited a physiological action analogous to that of the other xanthin-derivatives. Paraxanthin also possesses a distinct action on the respiratory apparatus, since, in all cases in which any effect was produced, the lungs were found to be strongly inflated. He was unable to examine the action of heteroxanthin, from the smallness of the quantity in which it can be obtained.--Dr. Baginski demonstrated the reducing action of certain Bacteria, using, as a reagent, methylene-blue, which becomes colourless by reduction. The Bacteria were obtained from the intestines of healthy cows. Both $B a c$ terium lactis and Bactirium coli produced a powerful reducing action in pure cultivations, where the nutrient fluid was coloured with methylene-blue; in those places where oxygen had access the blue colour reappeared. A third Bacterium discovered by the speaker exhibited no reducing power.--Prof. Gad explained, on behalf of $\mathrm{Mr}$. Donaldson, the method introduced by Prof. Martin, of the Johns Hopkins University, Baltimore, of isolating the mammalian heart, and of making observations on its activity for several hours, when isolated from the body and connected only with the lungs. The defibrinated blood which flows from the aorta passes into two Mariotte flasks which are in communication with each other, and thence into the right auricle. By means of this arrangement it can be shown that the heart, when separated from all its nerve;, works quicker when the temperature of the blood is raised, and slower when it is lowered. An increase of pressure in the aorta was found to be without any effect, whereas an increased venous resistance increases the cardiac activity. It could not be shown that the heart exerts any suctional action during its diastole.

Meteorological Society, December 6.-Prof. von Bezold, President, in the chair.- The President drew attention to Prof, Hann's two most recent publications, namely, the "Atlas of Meteorology" and "The Barometric Pressure in Middle and South Europe according to Observations extending over Thirty Years," and gave a short account of their contents.-Dr. Assmann gave an account of the experiments he has carried on during the last year and a half with a view to determining the true temperature and humidity of the air. After describing the methods previously used to determine the true temperature of the air and his own unsuccessful attempts before he arrived at a satisfactory result, he explained the principle of the thermometers as finally employed, and demonstrated the same by exhibiting several of them. These instruments consist of a fine sensitive mercurial thermometer, of which the small bulb is surrounded by a highly burnished cylinder of nickel-plated brass, open at the lower end. 
At the upper end the brass cylinder has a lateral opening by which its interior can be connected with an india-rubber aspirating ball. The chief difficulty met with was in the construction of a suitable valve for the aspirating ball. Finally he succeeded in making a valve such that no air was ever driven back towards the thermometer when the ball was compressed, but only drawn over the bulb of the instrument during the aspiration at the rate of $\cdot 2$ to $2 \cdot 5$ metres per second. Within these limits the rate at which the air is drawn over the bulb had no influence on the temperature recorded by the thermometer. Of extreme importance, as showing the suitability of the instruments, were the speaker's observations on the temperatures recorded by two of his thermometers, of which one was exposed to the direct rays of the sun, while the other was shaded by a distant shutter: the two thermometers recorded the same temperature, while at the same time an actinometer exposed to the sun showed a temperature $17^{\circ} \mathrm{C}$. higher. The same exactness in the determination of the humidity of the air is obtained when a pair of these thermometers is used, and the bulb of one is wrapped round with a piece of moist cloth. This instrument is specially suitable for observations in a balloon. The speaker explained that only shortly before the present meeting he had found that a similar instrument had been constructed by Welsh about the year 1850 . -Dr. Robert von Helmholtz gave an account of experiments which he had carried on conjointly with Dr. Sprung with a view to determining the humidity of the air. They had both arrived, independently of each other, at the idea that the determination of the dew point might best be made, not, as in the usual way, by the condensation on the bulb of a thermometer, but by measurement of the amount of rarefaction which the air must undergo in order that a mist may be produced. In a previous research the speaker, when determining the vapour-tension over solutions of salts, had compressed the air in a closed space, and then obtained a formation of mist by suddenly reducing the pressure again to that of the atmosphere. By determining the general excess of pressure which is thus requisite, the dewpoint may be determined. Dr. Sprung has compared the dew-point as thus determined and as obtained by Regnault's apparatus. The experiments are not yet carried sufficiently far to yield any numerical results, but even now it may be said that this new method of determining the dew-point is extremely trustworthy.

Physical Society, December 9.-Prof. du Bois Reymond, President, in the chair.-Dr. Badde developed the mathematical formulæ by means of which he can determine the vibrational condition not only of a vibrating string, but also of a square plate-formulæ which make it possible to determine the relation between the pitch of the note and the vibration-amplitude of the vibrating plate.-Dr. Pringsheim gave an account of the experiments he has made, in conjunction with Dr. Summer, to determine the quotient $(k)$ of the specific heat of gases. The value of $k$ is determined either by measuring the rate of propagation of sound in gases which obey Mariotte's law, or else from the ratio of temperature to pressure when the volume is kept constant. Up to the present time the rate of transmission of sound has not been so exactly determined that the values can be used for deducing the value of $k$. Similarly the second method has as yet given very discordant results, while at the same time the experiments have not been free from errors. Drs. Pringsheim and Summer have c.mpressed air in a glass balloon whose capacity was sixty litres, and determined its temperature by means of a fine silver wire passing through it whose electrical resistance was known. Hereupon the pressure in the balloon was allowed to sink to that of the atmosphere by opening a tap leading into it, and the cooling thus produced measured by means of the wire. Immediately upon this the tap was again closed, the air becoming warmed by the heat which passed into it from the air surrounding the balloon, and the rise of temperature again measured. During these experiments it was found to be of no conseguence whether the rarefaction of the compressed air took place rapidly through a tap with a large bore, or through one with a narrow aperture; the wire always showed the same amount of cooling, thus proving that it follows the alteration of temperature of the air very rapidly. Similarly the length of the wire was found to have no effect on the results, thus showing that the temperature of the surroundings has no influence on the temperature recorded by the wire. The resistance of the wire was determined by the irridge-method, partly by means of a galvanometer, partly by weans of a telephone. The ratios of the alterations in resistance of the wire to alterations of temperature were determined, within the necessary limits, for several fine wires. The speakers considered that the only objection which can be raised to their experiments is that the above determination was not made with the same wires which were used in their experiments, and they propose to do away with even this objection by some later experiments which have not as yet been carried out. All other possible objections have been set aside by varying the conditions of their work while obtaining constant results. As a mean of the separate measurements they obtained as a value for $k$ the number $\mathrm{I} \cdot 384$; the deviation for the mean value amounted only to a few hundredths per cent. The above value for $k$ cannot however be taken as being absolute until it has been proved that there is a proportionality between the temperature and resistance of the silver wire which thev used in their experiments.

\section{BOOKS, PAMPHLETS, and SERIALS RECEIVED.}

Ferrets and Ferreting, and edition (U. Gill).-Massachusetts Institute of Technology : 23 rd Annual Catalogue of the Officers and Students, \&c. (Boston).-Die Theekultur in British-Ost-Indien; Hist. Naturwissenschafftich und Statistich (Prag). - Quarterly Journal of the Royal Meteorological Society, October (Stanfurd).--Annalen der Physik und Chernie, 1887, No. 12 (Leipzig). - Archives Italiennes de Biologie, to ne ix. fasc. I (Turin). - Journal of the Royal Microsc spical Society, December (Williams and Norgate).-Elementary Text-book of Physiography: W. Mawer(Marshall). - Management of Accumu'ators, 3 rd edition: Sir D. Salomons (Whittaker). - Sewage Treatiment, Purification and Utllization: J. W. Slater (Whittaker). -Flour Manufacture : F. Kick, translated by H. N. P. Powles (Lockwood). - Photography Simplified, ${ }^{\text {rd }}$ edition (Mawson and Swan).--Transactions of the Sanitary Institute of Great Britain, vol. viii. (Stanford). - A Treatise on Chemistry, vol. iii. Part 4, Organic Chemistry : Roscoe and
Schorlemmer (Macmillan).-Present Religion, Part 2: S.S. Hennell (Trübner).-Die Altchriftliche Fresko und Mosaik-Malerei : Dr. O. Pohl (Leipzig). - Recherches sur l'Iso'ement du Fluor: H. Moissan (GauthierVillars, Paris). - Iournal of Physiology, vol. viii. No. 6 (Cambridge). Morphologisches Jahrbuch, xiii. Band, 2 Heft (Williams and Norgate).

\section{CONTENTS.}

PAGE

The Rosicrucians . . . . . . . . . . I93 The Mechanics of Machinery. By Prof. A. G. Greenhill ............. 195

The Solomon Islands . . . . . . . . . . 196 Crown Forests at the Cape of Good Hope . . . . 198 Our Book Shelf :-

Denslow and Parker: "Thomas A. Edison and Samuel F. B. Morse" . . . . . . . . I Wright : "Sound, Light, and Heat" . . . . . I99

Layard: "Through the West Indies" . . . . . . I99

\section{Letters to the Editor:-}

"The Conspiracy of Silence."-Samuel F. Clarke ; An Old Pupil of Wyville Thomson's . .
Greenland Glaciers.-Prof. Joseph Prestwich, F.R.S. "The Mammoth and the Flood."-Henry H. Howorth, M.P.; Your Reviewer . Centre of Water Pressure.-George M. Minchin . The Recent Earthquakes in Iceland.--Th. Thoroddsen

The Canary Islands, -Olivia M. Stone . . . . .

The Ffynnon Beuno and Cae Gwyn Caves.--Dr. Henry Hicks, F. R.S. . . . • . . .

Distorted Earth Shadows in Eclipses,-Capt. Henry Toynbee . . . . . . . . . . . 202 Dr. Balfour Stewart, F.R.S. By Prof. P. G. Tait . 202 Christmas Island. By J. J. Lister; Capt. W. J. L. Wharton, F.R.S.

Timber, and some of its Diseases. II. (Illustrated.) By Prof. H. Marshall Ward . . . . . . . . 204

Notes . . . . . . . . . . 207 Astronomical Phenomena for the Week 1888 January I-7 . . . . . . . . . . . 210 Geographical Notes .......... 2 II Journal of the Royal Agricultural Society. By Prof. John Wrightson ............2II The Reproductive Organs of Alcyonidium gelatinosum.

By Prof. W. A. Herdman . . . . . . . . 2r3

Societies and Academies ......... 213 Books, Pamphlets, and Serials Received..... 216 